\title{
Universiteit
}

Leiden

The Netherlands

\section{Wikipedia as Distributed Knowledge Laboratory: The Case of Neoliberalism}

Tatum, C.C.; LaFrance, M.; Jankowski N.W.

\section{Citation}

Tatum, C. C., \& LaFrance, M. (2009). Wikipedia as Distributed Knowledge Laboratory: The Case of Neoliberalism. In E-Research: Transformation in Scholarly Practice (pp. 310-327). Routledge. Retrieved from https://hdl.handle.net/1887/31861

Version: $\quad$ Not Applicable (or Unknown)

License: $\quad$ Leiden University Non-exclusive license

Downloaded from: $\quad$ https://hdl.handle.net/1887/31861

Note: To cite this publication please use the final published version (if applicable). 


\title{
17 Wikipedia As Distributed Knowledge Laboratory The Case Of Neoliberalism
}

\author{
Clifford Tatum and Michelle LaFrance
}

\section{INTRODUCTION}

In recent years collaborative web applications, such as wikis and blogs, have redefined our understanding of knowledge practice as they have subsequently changed the standard practices of collaborative research. At these sorts of sites, academics, knowledge workers, and enthusiasts contribute to the emergence of new forms of mediated discourse and collaborative knowledge production, exploring the value of shared computational resources and distributed access to datasets under the rubric of cyberscience (Nentwich, 2003: 21-25). Such new forms of technological mediation and collaboration compel the examination of resulting changes in research practice, referred to by some as 'e-research' (Wouters \& Beaulieu, 2007).

In the humanities and social sciences collaborative practices have emerged more readily in less formal knowledge exchange environments, such as email lists, academic blogs, and content repositories, where the exchange and negotiation of ideas trumps the often rigid practices of scholarly peer review. While attention has been paid to the use of information and communication technologies (ICTs) in academic knowledge production, scholars have only just begun to realize the potential of these tools to demonstrate how knowledge comes to be accepted as valid and reliable.

Wikipedia is a place where many of these emergent practices and realizations are flourishing. In this chapter, we examine the distributed collaborative processes in a Wikipedia article as a potential model for the practice of academic research. Although Wikipedia contributors are not conducting primary research, the encyclopedic assemblage of knowledge in articles requires intellectual negotiation of new knowledge, particularly with respect to defining what is in and what is out of an article. ${ }^{1}$ Emergent forms of collaborative knowledge production are also apparent in the negotiations of content, structure, and categorization of new articles. As such, Wikipedia exemplifies the tremendous potential of emergent ICT field sites for studies of knowledge practice, realized in both its highly structured, but professionally open environment, and the archival function of the site 
that records each and every keystroke to provide a detailed account of page content under development. The discussion log accompanying Wikipedia articles provides particular insights into how article content is co-produced among varied and distributed participants.

Simultaneous to the phenomenal success of Wikipedia, there has been considerable diffusion of ICT use in the social sciences and humanities. The openness and inclusiveness of ICT use has created an uncomfortable fit with research-oriented scholarship. A tension of cultural values exists between academic communities of practice and popular usage of these new technologies. ICTs and the Internet cultivate an open-some might say a radically open-ethic that conflicts with protections of intellectual capital embedded in the quality control measures of scholarly knowledge production. Cultural change is slow in the humanities and social sciences, so the changes embedded in increased ICT and Internet usage are more apparent within the contexts of informal scholarly communication, which shares a common set of emerging knowledge practices with popular usage of these technologies. Much of the discourse around the implications of these knowledge practices claims either that knowledge is being diffused to the masses, like in the Wikipedia case, or that we are in the midst of radically new forms of knowledge production (e.g., Arms \& Larsen, 2007). Elements of both these claims are likely true, enticing us to ask to what extent on-line mediated knowledge practice will follow established and recognizable processes of knowledge production. To answer this question and to gauge the applicability of ICT-mediated knowledge practice for use in collaborative research, we examine the construction of a single Wikipedia article about the political economy concept, Neoliberalism.

In this essay, we use qualitative and content analyses to demonstrate how authors discursively negotiate the content, categories, and structure of Wikipedia's article on neoliberalism. To provide an analytical framework for the Wikipedia process and a baseline definition for knowledge production, we rely upon Latour and Woolgar's (1986) study of the construction of facts in a scientific lab, Laboratory Life: The Construction of Scientific Facts. In this text, Latour and Woolgar demonstrate that the production of factual knowledge follows typical patterns and is often reliant upon styles of communication, factors of persuasion, and other non-scientific contexts of practice than truly 'objective' observations or measurements. We couple Latour and Woolgar with the Wikipedia article on neoliberalism, in particular, because the article's archives offer an excellent example of the multiple processes of negotiation authors must undertake for their assertions to be considered 'fact'. This chapter proposes that analysis of Wikipedia's page on neoliberalism enables a rigorous understanding of typical ICT-mediated knowledge practice, as similar processes of 'factual' content construction commonly recur in other collaborative online knowledge production situations. 


\section{BACKGROUND: (SOCIAL) CONSTRUCTION}

In recent years, scholars in the humanities and social sciences have increasingly argued that knowledge always exists in relationship to social conditions and social norms-this obviously places the individual's ability to know or to produce new knowledge into the context of their social circumstances and surroundings. The traditional positivist account of knowledge, however, holds that what we know is empirically constant and what we wish to know can be revealed or discovered through systematic, rigorous analysis. These two positions bookend a debate about how we arrive at 'knowledge' and what cultural forces or processes of analysis will expose the factual basis of that knowledge. In the 1970s Bruno Latour and Steve Woolgar conducted an ethnographic study of scientists at the Salk Institute for Biological Studies, a neuroendocrinology lab, aiming to determine the role of social factors in the process of fact construction and the scientific reception of new knowledge. The results of their study highlight the numerous non-empirical social factors that invade and mold the sanctuary of knowledge production, the scientific lab.

The overarching argument put forth by Latour and Woolgar (1979) is that social, intellectual, and technical factors, all play a role in establishing-or constructing-facts. Their work touched off an enduring discourse around the nature of factual knowledge. At the height of the social construction debate, numerous scholars suggested that the relationship between 'reality' and the 'constructed' was more complex than social constructionists allowed. Latour and Woolgar did not dismiss issues of realism or objectivity (1986: 176), but admitted their first reports did not account for the existence of an objective reality or recognize that some natural phenomena exhibit repeating, enduring, and often measurable characteristics independent of scientific description and/or evaluation. These arguments reveal an anxiety prevalent in scientific communities around the extent to which factual information or evidence may be molded by the context of its production; the apprehension is that some knowledge must be free from social interference or it loses validity.

Herein lies an important distinction for thinking about the puzzle of Wikipedia as a collection of facts. Latour and Woolgar do not take the position that facts are somehow degraded due to the social conditions of their production-their study reveals the extent to which knowledge production and the production of 'facts' are always collaborative processes situated in an array of encroaching social practices. Facts themselves are still 'indifferent', according to Latour and Woolgar, even if the process by which facts are established entails the sort of collaborative negotiations that would seem to erode their grounding in objectivity. Participants in knowledge production always negotiate the stakes, priorities, and conclusions attached to the acceptance of particular facts. Publication of Laboratory Life was a move toward better understanding of social, political, 
economic, and other contributions to the construction of knowledge in scientific settings (Sismondo, 2004). Whereas other scholars may cling to distinctions between knowledge and reality, particularly to differentiate the constructed and the real, Latour and Woolgar generalize that processes of negotiation are always central to the establishment of facts.

While the Wikipedia phenomenon has introduced new ways of thinking about mediated collaboration, it also provides a baseline account of ICT mediated factual construction. The discursive construction of article content bears a striking resemblance to the process of fact construction in a scientific laboratory as noted by Latour and Woolgar. Wikipedia's article on Neoliberalism emerged over a five-year period; analysis of the article's participant discussions reveals that construction of the article's facts has so far taken place in three distinct, but intermittent cycles over that five year period-we borrow from Latour and Woolgar to name these three cycles and their interrelated processes: construction through the agonistic field towards reification. Though we must note differences in the degree of stability related to social content and the openness of online collaboration, such cycling of the construction of fact process is consistent with Latour and Woolgar's constructionist framework (1986).

The Latour and Woolgar argument is comprised of six interwoven sociological elements. Three of these elements, construction, agonistic field, and reification, are process-oriented and are the basis for the analytical framework used in this study. The other three elements, credibility, noise, and circumstance, are contextually based criteria. For example, credibility is a result of the various investments made by scientists; credibility facilitates the synthesis and validation of economic and epistemological contributions to the field of research. The element of noise is similar to the concept of a signal-to-noise ratio, whereby wave signals must be distinguished from the surrounding cacophony of irrelevant noises to be 'audible' or valid. The element of circumstance points to the notion that scientific practices exist within an array of specifically localized practices. Contextual elements noted in the Latour and Woolgar study are likely present in Wikipedia, but beyond a brief nod to notions of the prestige or rhetorical muscle of the most persuasively effective Wikipedia contributors, these elements are outside of the scope of this project.

The first of the three process elements identified by Latour and Woolgar, construction, refers to the slow process whereby an account or an assertion is simultaneously crafted as it is circulated through the relevant scientific community. Construction is perhaps the most profound of the dimensions mentioned by Latour and Woolgar because it recognizes that even an initial assertion is socially embedded and that the testing of assertions is not separable from their acceptance as fact. Splitting and inversion are subsequent recursive processes, named by Latour and Woolgar, whereby inscriptions are comprised of discreet data points that congeal into a cohesive statement about the thing (object) of study. Initial acceptance by the scientific 
community, the building up of supporting data points, and the lack and/ or presence of equally probable explanations contribute to the splitting and inversion of new knowledge. Arguments for or against particular facts exist in a constant state of fluctuation and are stabilized only over time.

Once the statement begins to stabilize, however, an important change takes place. The statement becomes a split entity. On the one hand, it is a set of words, which represents a statement about an object. On the other hand, it corresponds to an object in itself, which takes on a life of its own. It is as if the original statement had projected a virtual image of itself, which exists outside the statement (Latour \& Woolgar, 1986: 176).

Whereas construction is concerned with data and analysis, the agonistic field is concerned with the ways in which the statements are positioned by the researcher and perceived by their community of practice. That is, the agonistic field is where scientists qualify given statements through the interplay of argumentation and persuasion. Persuasive factors may include the unexpectedness of a particular point, the personality and institutional attachments of the author-researchers, the stakes, and/or the style of the paper. Assertions made by authors with inadequate professional reputation or with too many equally probable or alternative explanations will acquire little endorsement from the community. An assertion without sufficient endorsement will require the researcher to persuade and inform their peers such that unequal plausibility can be achieved. Finally, reification, the end result of the disorderly negotiations in the agonistic field, refers to the tacit manifestation of a statement; a statement is reified once it has stabilized, that is, it is no longer under dispute by members of the community. Another way of thinking about this is that the intellectual foundations in a research effort are built upon prior facts. Once a fact is generally accepted, it then becomes a part of the intellectual capital within the laboratory and the larger community of practice.

To summarize, if all assertions were perceived as equal among collaborators, they would be deemed inadequate. However, if there is unequal probability among competing assertions, it is the most unexpected, or, more importantly, the most persuasive assertion that gains the attention of the scientific community. Perceptions of higher probability are likewise based on a number of factors such as investment or intellectual effort, researchers' abilities to gather evidence, the evidence itself, and, tellingly, the professional reputation and the persuasive abilities of the presenter. When sufficiently convinced, peers stop raising questions; the assertion is no longer held to subjective scrutiny (Latour \& Woolgar, 1986: 239-240).

These discursive moves, particularly the negotiation towards and acceptance of some points as more pertinent and effective than others, provide a compelling analogy to the collaborative practice embraced by Wikipedia contributors. To show how contributors employ this framework in an online environment, in the next section, we will present a methods strategy for online analysis and demonstrate how it corresponds to Latour and Woolgar's ethnographic approach. 


\section{METHODS STRATEGY}

According to the text on the Wikipedia article we examine,

Neoliberalism refers to [the] historically-specific reemergence of economic liberalism's influence among economic scholars and policymakers [since] the $1970 \mathrm{~s}$... the term is used to denote a group of neoclassical-influenced economic theories and libertarian political philosophies which believe that government control over the economy is inefficient, corrupt or otherwise undesirable.

Readers will note that even this rudimentary definition was under (re) negotiation as we drafted this article. Competing definitions on the site tended to reflect the highly charged valence of political terminology in light of the left/right dichotomy of current U.S. politics. As such, the article's primary authors can be seen on the discussion pages explaining, citing, cajoling, and appealing to previously hard-won points of consensus, Wikipedia's standards for content development, and other forms of authority in order to make progress toward common understandings of the term. Our interest in what may or may not constitute neoliberalism ends here; instead, we turn to the site's archival discussions as they demonstrate the negotiation of content, which is our primary interest. As we have stated, discussions among distributed authors demonstrate the very nature of collaborative knowledge production, "[T]he marketplace of ideas that has made Wikipedia a good source when it works well" in the words of the frequent author known as jncohen.

Because we are concerned with the negotiations of content that result in the reification of knowledge on Wikipedia, we draw from Computer Mediated Discourse Analysis (CMDA) to qualitatively describe the broad processes of collaboration, contest, and assertion that are active in the creation of the article on neoliberalism. In the broadest sense, our analysis privileges "discourse as social interaction" to understand artifacts produced though online collaboration (Herring, 2004). As the primary analytical means of this study, discourse analysis serves to facilitate qualitative empirical examination of the discussion among contributors of a Wikipedia article. In addition to discourse analysis, we use content analysis to more closely examine and quantify the collaborative activity of the page on neoliberalism. We measure the 'edit' activity in both the article and on the talk page, and we show the frequency, as well as degree, of change in the article itself. By using a single article as our case study, the discourse we examine is internally coherent and contextualized in a bounded sample of interaction (Herring, 2004).

Latour, in his later work on actor-network theory (2005), accounts for a similar intensive interest in practice by noting that the "reason why we went to study the laboratories, active controversies, skills, instrument 
making, and emerging entities was to encounter unstable states of nature/ society and to document what happens in those extreme and novel situations" (Latour 1991: 287 as cited by Miettinen, 1999). Similarly, Foot and Schneider (2006) orient their work on Web campaigning to a practice-based theorizing. Like in the study of activity systems (Foot, 2001), a focus on practice "suggests that tools-both material and symbolic-are created and transformed within practices" (Foot \& Schneider, 2006: 12). Online environments pose some difficulty in examining practice due to the asynchronous mode of activity and the dispersal inherent in ICT mediated work. Wikipedia's precise and exhaustive archive, however, makes it an ideal location to research on-line practices such as collaborative knowledge production.

As the figure below shows, the page on neoliberalism includes a unique URL and is comprised of four tabs along the top of the page (See Figure 17.1). The default tab is the article itself. The other three tabs reveal the talk page, the edit page, and the edit-history of the article. There is also an edit-history page for the discussion text. Interaction among Wikipedia authors occurs simultaneously in two locations: in the article content and in the online discussion of the article's composition. The authors' discussions about the article is the primary dataset for this study. The article itself provides a contextual reference and structural markers for that discussion. The edit history data provides a sense of time-span and frequency for all content edits.

\section{COMPETING DEFINITONS OF NEOLIBERALISM}

The Wikipedia article on neoliberalism languished for nearly two years as a small summary article that received little attention; this changed in the beginning of 2004 when the first of three phases of debate and collaboration began to enliven, expand, and reify portions of the article. The first phase was marked by negotiated generation of content; the next was

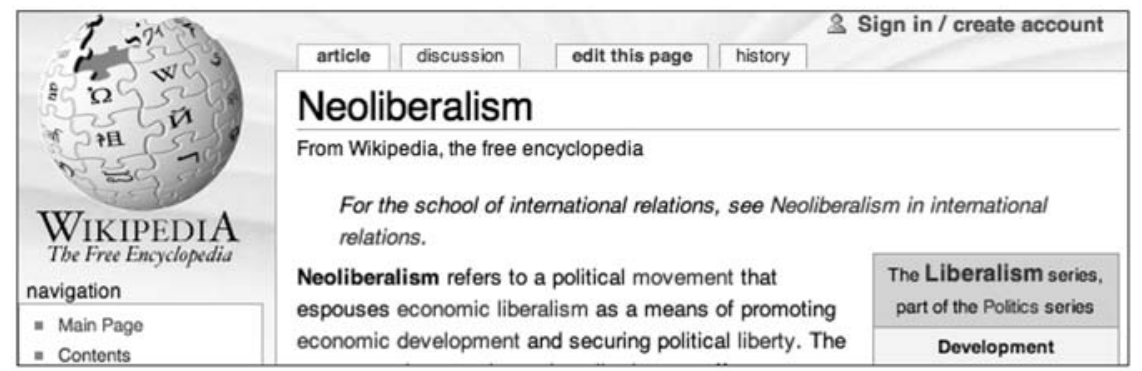

Figure 17.1 Wikipedia page layout. ${ }^{2}$ 
characterized by a debate around the neutrality of the article's point of view (POV) including challenges to word choice and questions of the political investments/affiliations of the contributors; and the third was a phase notably concerned with the suitability and authority of academic citations included in the latest version of the site. The content generation phase began in earnest when the article grew from less than a thousand words to approximately three thousand words. Contributors then began to refine the content and strengthen the article by working towards a neutral point of view. Whereas the first phase was focused on filling out the content and defining the initial structure of the article, the second and third phases were marked by discussions of perceived bias in the existing content and situating the article in academic literature. Although earlier phases used citations to reference content and basic definitions, this last phase saw considerable effort to specifically align article content and structure with arguments in the domain of political science. As this chapter will show, these three phases correspond with Latour and Woolgar's (1986) construction of facts framework.

Contributors' edit activity reveals the invention and subsequent negotiation of new content, the competition among ideas in the agonistic field, and reification of knowledge into factual object-status-all consistent with the framework described by Latour and Woolgar. However, taking a macro view of the three phases reveals that each phase has a particular focus that also corresponds to steps in the framework. Edit activity in the first phase of content generation is more heavily oriented to article construction. In the second phase, point of view debates are best understood as exercises in resolving the divergence of several points of view. This very clearly represents activity in the agonistic field. And finally, revising the article in line with relevant scholarship through the discussion and application of citations demonstrates the reification of the article as fact. Multiple fact construction processes can be seen to be occurring simultaneously at different phases in the article and at different levels of the article. Moreover, the crucial moment of splitting and inversion also occurs simultaneously and at multiple levels. For the purposes of this study, we provide an analysis at the level of the three phases, rather than inside of each phase.

\section{Content Analysis}

The Neoliberalism article is larger and somewhat older than the statistical mean among all articles written in the English version of Wikipedia. For example, Wikipedia users have averaged 17 edits per article out of a total of nearly 200 million edits. ${ }^{3}$ By comparison, the article on Neoliberalism was started over five years ago in September 2002 and by December, 2007 had accrued nearly 1200 edits (see Table 17.1) with roughly 515 uniquely identified contributors. ${ }^{4}$ Contribution varied among authors, however, and the distribution revealed adherence to the power law associated with networks 
(Barabasi, 2003), which predicts that a small minority of users will contribute most to construction of the article. This distribution of author activity is illuminated by Anthony, Smith and Williamson (2005); quality contributions come from both anonymous 'Good Samaritans' who don't contribute very often, and committed 'Zealots' who contribute regularly. While the article itself was 6,500 words in length in December 2007, the talk page with a total of 122 contributors had a cumulative word count of 24,000. That the article had four times as many edits as the talk page, but only a quarter of the word count is characteristic of their respective functionsthe article is revised through additions and deletions and the talk page is an on-going discussion. While the article has been in perpetual revision, including large quantities of added and deleted content, the talk page archives the entire background discussion about the article.

Edits to both the content page and talk page are tracked and can be viewed on their respective history pages. Each individual edit can be viewed and compared with any other version of the article or talk page. Figure 17.2 below illustrates edit activity of both the article and the talk page over roughly five years of article construction. The dashed line shows article edit activity of nearly 1200 unique edits over five years. The dash-dot line shows the corresponding edits in the talk page. Three distinct increases in edit activity correlate with the three construction phases. By contrast, the article word count shows construction and revision of the article over the same time period. Variation in word count provides a measure of change in the content in conjunction with frequency of edits. The periodic presence of vertical lines in the article word count curve show instances of mass deletion of text and that very soon after another contributor will typically revert the article to the last version. More recently automated scripts or 'bots' monitor this form of vandalism and automatically revert content back to the previous version. These edits, the simple addition and subtraction of

Table 17.1 Edit Distribution among Contributors to the Neoliberalism Article \& Talk Page

\begin{tabular}{lcccc}
\hline & \multicolumn{2}{c}{ Article } & \multicolumn{2}{c}{ Discussion } \\
\cline { 2 - 5 } $\begin{array}{l}\text { Number of } \\
\text { Edits }\end{array}$ & $\begin{array}{c}\text { Number of } \\
\text { contributors }\end{array}$ & $\begin{array}{c}\text { Percentage of } \\
\text { Total }\end{array}$ & $\begin{array}{c}\text { Number of } \\
\text { contributors }\end{array}$ & $\begin{array}{c}\text { Percentage of } \\
\text { Total }\end{array}$ \\
\hline 1 & 367 & $70 \%$ & 65 & $53 \%$ \\
$2-5$ & 135 & $26 \%$ & 43 & $35 \%$ \\
$6-10$ & 8 & $2 \%$ & 11 & $9 \%$ \\
$11-50$ & 3 & $2 \%$ & 3 & $2 \%$ \\
$>50$ & 2 & $0.38 \%$ & 0 & $0 \%$ \\
Totals & 515 & $100 \%$ & 122 & $100 \%$
\end{tabular}




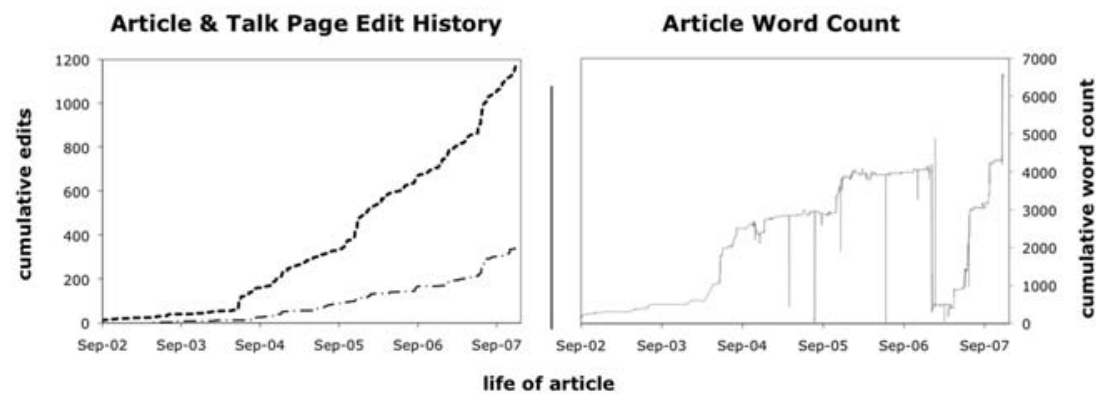

Figure 17.2 Neoliberalism article: Edit activity and word count.

text, are in fact the archival traces of negotiation over final word choice, organization of content, article structure, and ultimately more and more stable meanings upon which to further shared understandings.

\section{Content generation}

Two dominant themes run through the early discussion page. Within the first few lines of the first topic thread is the heading, "CALLING ALL WIKI EDITORS HERE!" This heading calls attention to an effort to define the fundamental meaning of neoliberalism. Of course the article itself is dedicated to defining the concept and political affects of neoliberalism; the endeavor to arrive at a basic definition of the word, however, permeates nearly all of the topics of discussion. This attempt at definition fits the criteria of Latour and Woolgar's concept of construction, indicated by the growth of new collaborative content that is accepted and/or uncontested, and thus results in negotiated terminology and a first draft of the article. Splitting and inversion, as defined by Latour and Woolgar, occurs when the words describing neoliberalism become an entity separate from the description. At this point the statement and idea correspond such that the statement represents the idea and established descriptions become conceptual building blocks in further development of the article. By contrast, a single input, although uncontested, would not yet meet the criteria for construction or splitting. This is because it is not yet clear if others have reviewed it. Construction, as such, can be said to occur either as a process of collaboration marked mostly by consensus, where acceptance of the knowledge introduced is implicit due to the lack of contests and challenges to that knowledge, or through explicit approval on the discussion boards about individual or collaborative input.

For example, while discussing possible definitions of neoliberalism, authors used two tactics; they argued about brief definitions and they asserted alternate terms as a measure of similarity and dissimilarity. Numerous alternate terms appeared throughout the discussion threads 
to explain neoliberalism via synonyms and antonyms; the applicability of alternate terms depended on the author's context and perspective. The term neoconservatism appeared in one case to argue that neoliberalism "is" neoconservatism: "is there any real difference between neoliberalism and neoconservatism?" Another author responded that neoliberalism is the opposite of neoconservatism. Yet another author proposed a merging of the neoliberalism and the neolibertarianism articles. And still another proposed that the term be changed altogether to "economic neoliberalism." Many other terms were debated and considered, such as "monetarism," "mercantilism," "new school of liberalism," and even "religious fundamentalism." The eventually reduced set of definitions showed a congealing of the basic notion of neoliberalism. Instead of open-ended debates, authors began proposing more concise definitions, more often employing terms that had evoked less contentious responses or that elicited little contest at all. Specific ideas emerging from the general discussion indicate a build up of discrete written contributions. While no explicit agreement had been arrived at through discussion of the correct definition, after numerous iterations of the article itself, a stable, less explicitly biased description emerged.

\section{Point of view}

The second phase of article construction is characterized by the discussion of a neutral point of view (NPOV)-the cornerstone of Wikipedia's collaborative authoring paradigm. The discussion of NPOV is best understood as activity in the agonistic field because it readily frames the debate about accuracy of the article. Although persuasion and argumentation are present throughout the article, there was a nearly five-month period (29 May 2005-14 October 2005) that the article was deemed to be in a state of disputed neutrality. In the Wikipedia environment, anyone can add a tag to the article indicating that the article's neutrality is in dispute. The article remains active and editable, however, with a neutrality dispute placard in the header (see Figure 17.3). Activity in the agonistic field is operationalized for this study as the argumentative and persuasive assertions among the authors within the discussion area. It is in the agonistic field that authors dispute content, justify edits and deletions, argue factual and theoretical points, and reference authoritative literature. Indications of the agonistic field are found directly in the threaded discussions.

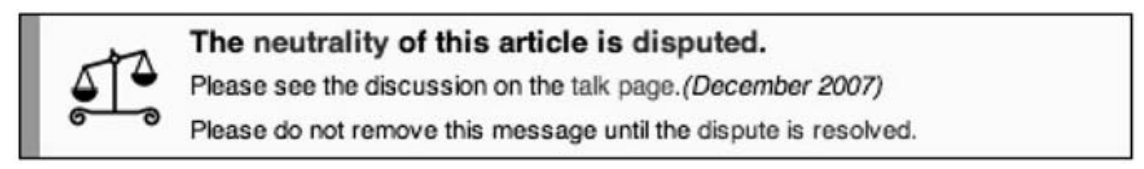

Figure 17.3 Neutral Point of View (NPOV) Placard. ${ }^{5}$ 
Two of the initial 25 discussion topic headings specifically addressed neutrality. Titled NPOV and POV, these two sections were small contributions to the overall discussion of neutrality. However, the two entries occurred in or near the period of disputed content. Whereas the construction discourse is comprised of a series of assertions, discourse in the agonistic field is generally more aggressive. This was the case during this first period of the disputed neutrality. Authors' comments included phrases such as, "I really have to disagree with that," "I think the problem here is ...," "This is not entirely true," and "You economists are just silly." While the increasing presence of references, the persuasiveness of the debate, and the rather antagonistic nature of dispute over content are all activities characteristic of the agonistic field, it is the dispute over neutrality that most illustrates the occurrence of activity in the agonistic field.

Further, the prolonged nature of the neutrality dispute corresponds with the parsing of article content into categories; the hierarchical organization of content indicates that multiple authors negotiated the relative importance of content elements. Growth of the article's table of contents corroborates this point. In the first phase, the table of contents was brief and focused on theory and practice. By the second phase, as a result of the difficulties during the first phase, a section called "People," about who counted as a neoliberal, was added. In the point of view debate contributors connected theories to theorists to facilitate arguments. The section of the article titled "Who is neoliberal?" initially served as a vehicle to categorize theories in terms of the larger debate. Claims of bias and of contributor point of view were later explicitly reformulated into competing theoretical positions about neoliberalism.

\section{Citation integration}

The third phase of the article on Neoliberalism is marked by extensive rewriting of the article to bring it into line within academic literature. This activity once again displays indication of all three steps in the construction of facts but, with reification of facts as the dominant modality. Notably, this phase also marked the emergence of two key authors, both academics, who orchestrated a shift in discursive tone and from what can be characterized as a Wikipedia hobbyist tone to more professional tone with disciplinary standards and practices. This is vividly displayed in the short talk page section titled, "are you kidding me?" In this sarcastic quip, an anonymous writer challenges the article as a "piece of biased shit." In response, a selfidentified academic and dominant contributor asks, [instead of complaining in the talk page] "why not actually contribute ... and add some cited material from intellectuals that you deem fit."

Reification in the laboratory context is the part of the process whereby a position stabilizes from an assertion to emerge as a fact. In the Latour and Woolgar sense, this happens when the assertion is no longer disputed 
and is integrated into practice. Due to the inherent fluidity in open content environments, indication of reification is somewhat problematic: a Wikipedia article is never actually 'finished,' as edits are made directly on the live article pages. As such, reification in this article is best illustrated by the authors' efforts at rewriting the article in the larger context of published scholarship on political economy. In this way the concepts of neoliberalism are stabilized within the accepted boundaries of established disciplinary arguments. Past versions of the article referenced source material through external links to other online resources. During this time period the word count graph shows a near complete deletion of old content and a stepped rebuilding of the article in chunks (see Figure 17.3). The article shows these chunks added along with relevant academic citations. In the Latour and Woolgar study, assertions and facts are also reified when they emerge in the practices of other laboratories. The analog for Wikipedia articles is that they become reified when they are once again stabilized, but this time within an accepted framework of existing literature. However, this reified state is likely only fleeting, as the notion of neoliberalism itself is still somewhat fluid and thus subject to new interpretations.

\section{DISCUSSION}

Even with its potential to devolve into an incoherent mash up of ideas, and in spite of widespread discomfort with an encyclopedia that everyone can edit, the collaborative construction strategies of the Wikipedia article on neoliberalism shows an ordered progression of factual construction over time. In spite of the openness of the Wikipedia platform, collaboration on articles about new social concepts is similar to processes of fact construction, especially the elements of construction and activity in the agonistic field, detailed by Latour and Woolgar in their work on the professional practices of scientific laboratories. Latour and Woolgar's findings stress the interdependence of sociological components in knowledge production and collaboration in order for the construction of facts to occur. This was consistent with our findings as we analyzed the construction of Wikipedia's article on neoliberalism, though reification, or stabilization, of facts in Wikipedia does prove to be a much more fluid concept. In the Wikipedia environment, reification occurs when the article content is no longer in dispute and/or when there is explicit agreement within the discussion. There is, as such, considerable overlap in the indicators of construction and reification. In part, this is a result of adapting the Latour and Woolgar framework to the online environment, though some level of stabilization of content and acceptance in the community characterizes them both.

To tease out the difference between construction and reification in Wikipedia we can look at construction as occurring within parts of content, sections, sub-sections, and particular ideas. Reification, then, would occur 
with the stabilization of the article as a whole. Acceptance of article construction occurs among the article contributors whereas reification is indicated by an acceptance of the article by the larger community. However, even with these distinctions, the fluidity of content challenges the notion of what it means for an article to be stable. Splitting and inversion occurs where certain statements about neoliberalism survive editing and gain acceptance as building blocks in the explication of the concept. In the agonistic field these textual building blocks serve to either further strengthen cohesive components of the article or are found to be inadequate and therefore deleted. And finally, each phase shows a state of reification where the article itself finds acceptance among the current set of editors. Additionally, when viewed as a group, the three phases exhibit the same sequence of construction. The first phase of content generation is itself representative of construction. The point of view debate in the second phase corresponds with the agonistic activity and the final phase as a whole reifies the content through the work of aligning the article with relevant literature in the field of political science.

Our analysis provokes further thinking around the adoption and adaptation of ICT mediated practices in the process of academic e-research. Whereas the construction of facts appears indifferent to the open content philosophy and the transparency of community practices that are the essence of Wikipedia collaboration, these qualities pose some problems for the academic model of collaborative research. Open content, the ability for anyone to edit Wikipedia, is a common source of fretfulness, but there is much less understanding of the extreme, some might say radical, level of transparency. The qualities of open participation and transparency hold great potential for academic and scientific practice, but they are also at odds with traditional mechanisms for quality control and disciplinary commitments that underpin knowledge claims.

\section{Academic Resistance to Open Content}

Academic blogs, academic email lists, open journals, digital repositories, and a variety of ad-hoc collaborative projects on the web point to a tension between the openness of ICT practices generally and the durability of traditional academic knowledge practices. This tension creates a kind of secondary market for knowledge, where ideas are exchanged, both published and unpublished works are presented, and where intellectual debates are enacted in the open and often with a more diverse, a more inclusive set of participants. Broadly speaking there are two ways of orienting this domain of scholarly discourse. On the positive side, contributors can claim the emergence of growing public scholarship where ideas more readily traverse disciplinary boundaries and the discussion is more engaging outside of the academy. On the negative side, opponents can claim that the openness of online scholarly discourse diminishes the role of peer review, disciplinary 
contributions, and other quality control measures, and thus weakens the value of new knowledge. Ideas flow more freely in an online environment than in traditional media of exchange such as conferences, workshops, and publications. The point here is not that ICTs are subverting peer review, nor that they should. Rather, that the values of transparency and access embedded in the open movement, although philosophically consistent with academic principles, are in conflict with the actual traditions of the academy.

To illustrate this tension, in a recent promotional video ${ }^{6}$ Jimmy Wales, the co-founder of Wikipedia asks us to "imagine a world in which every single person on the planet is given free access to the sum of all human knowledge." Two statements of fact are embedded in this statement. First, that not all people have access to knowledge, and second, that accessible knowledge is not all in one place. To accomplish what Jimmy Wales asks us to imagine is virtually impossible given the social and infrastructural complexities of overcoming the twin barriers of access to and containment of all human knowledge. To put this in an academic context: in April 2007, the National Science Foundation and the British Joint Information Systems Committee (NSF/JISC) held a workshop addressing "The Future of Scholarly Communication," about the use of ICTs in the practice of scholarship. The workshop was well attended with broad international representation from academic and governmental institutions as well as industry stakeholders. In their conclusions, the joint NSF/JISC claim that new ICTs, and the availability of digital content, create new and qualitatively different forms of scholarship (Arms \& Larsen, 2007). And further that, these new practices are contributing to a 'cyberinfrastructure' that enables 'novel forms of research'. The joint team argues that the biggest challenge to realizing new and innovative research and asking new and innovative research questions is the lack of a standard infrastructure. Crucially, it remains unclear what kinds of novel research practices are possible and the extent to which new mediated research practices can be adapted to academic modes of knowledge production.

That scholarship has changed in concert with ICTs is not in doubt. Wouters and colleagues (Wouters et al., 2007: 337) provide a comprehensive review of Science and Technology Studies literature and conclude that it is "empirically established that mediating technologies are influencing scholarly and scientific methodologies." The combination of forces in open research projects and academic traditions would seem to enable collaboration in ways previously unseen. For example, the combination of a premium on consensus and freely editable content enables a plurality of viewpoints in processes of knowledge production. While the neutrality of Wikipedia content is quintessential to their process and the potential for change is constant, how these factors affect and suspend meaning (Forte, 2003) is particularly problematic for the advancement of new e-research practices. Even stable and reified articles can be changed significantly as new participants enter the discourse and make edits or activate the agonistic field with 
new arguments. As Emigh and Herring (2005) point out in their study of Wikipedia, a few actors can circumvent the efforts of a larger group while absolutely working within established norms and disciplinary boundaries. Although the platform is stable, the article content cannot be because open content means that anyone can change any article with only a connection to the Internet and a Web browser. This points to a very different function for knowledge and knowledge practices as they emerge from sources such as Wikipedia. Whereas Wikipedia is a repository of knowledge, academic research must be more formally reified in order for it to function within the auspices of the academic disciplines. Nevertheless, an interdisciplinary collaborative project would benefit from all participants having simultaneous access to the real-time status of co-produced content on a wiki-type platform.

The dynamics of open content are already very similar to the culture of academia (Boettiger \& Burk, 2004). More specifically, "the general normative expectations in science are largely communitarian rather than proprietary. Scientific submissions to the public body of knowledge are based on reputation incentives and are only indirectly related to a maximization of future profits" (Boettiger \& Burk, 2004: 223). This similarity suggests that e-research collaboration and open content practices might be readily compatible. While it is true that hierarchy still exists in Wikipedia, barriers to participation are significantly less than in academic modes of knowledge production. There are significant implications for how we collaborate and what kinds of knowledge can be produced via open content projects.

In his well-known account, Raymond (2001) characterizes the development of open source software as a "babbling bazaar of differing agendas and approaches" (Raymond, 2001: 21) from which an efficient process and stable product emerges. This is as opposed to the more centralized management of software development, which can be viewed as tightly controlled "Cathedral-building". While, Raymond's object of study, the Linux project, did not topple Microsoft's dominant position in the Operating System market, the diffusion of Linux has contributed to structural changes in the industry, as well as in some instances the opening of Microsoft's practices (e.g., Gonsalves, 2007). Moreover, the growing use of blogs and wikis, for example, is providing access to alternative sources of knowledge that challenge authoritative sources (Rogers, 2004); these alternate sources of information are flouting the authority of traditional information and knowledge institutions (Bennett, 2003). To be sure, the very nature of working in a digital environment calls into question all sorts of boundary assumptions. Of particular interest here is the often discussed blurring of boundaries between producers and consumers of media, which is an important characteristic of changing knowledge practices.

Whereas scientific communication that follows the formal practices of conferences, workshops, symposia, and journal publications has been slow to adopt new technologies, it is in the informal modes of scholarly 
communication where adoption of ICTs is revealing the most visible changes in knowledge practices. The open content movement has contributed to changes in collaborative knowledge practice despite the lag in changes to the dominant structures of academic knowledge production. The opportunity to contribute to collective knowledge resources, such as, but not limited to, Wikipedia, has tapped into a pent up desire to contribute. The aggregate of large-scale contribution to online projects has the continuing potential to pressure dominant structures towards change. So while this emerging space will not topple the academic enterprise, it will likely continue to introduce structural changes in academic practice, and thus continue to give definition to e-research as a practice commensurate with the still evolving infrastructure standard.

\section{NOTES}

1. Wikipedia explicitly forbids the inclusion of primary research and regularly polices contributors' practices to maintain standards for article construction.

2. Source: http://en.wikipedia.org/wiki/Neoliberalism; accessed 28 January 2008

3. Source: http://en.wikipedia.org/wiki/Special:Statistics, accessed 7 December 2007.

4. Source: http://en.wikipedia.org/wiki/Neoliberalism, accessed 28 January 2008.

5. Source: http://en.wikipedia.org/wiki/Neoliberalism; accessed 28 January 2008.

6. Source: http://wikimediafoundation.blip.tv/\#447562, accessed 28 January 2008.

\section{REFERENCES}

Anthony, D., Smith, S., \& Williamson, T. (2005). Explaining quality in Internet collective goods: Zealots and Good Samaritans in the case of Wikipedia. Paper presented at the Economic Sociology and Technology Conference, Ithaca, NY, 23-24 September.

Arms, W., \& Larsen, R. (2007). The future of scholarly communication: Building the infrastructure for cyberscholarship. Report of the National Science Foundation \& British Joint Information Systems Committee. Phoenix, AZ, 17-19 April.

Barabasi, A. (2003). Linked: How everything is connected to everything else and what it means. New York: Plume.

Bennett, L. (2003). Communicating global activism: Strengths and vulnerabilities of networked politics. Information, Communication \& Society, 6(2), 143-168.

Boettiger, S., \& Burk, D. L. (2004). Open source patenting. Journal of International Biotechnology Law, 1, 221-231.

Emigh, W., \& Herring, S. C. (2004). Collaborative authoring on the Web: A genre analysis of online encyclopedias. Proceedings of the Thirty-Eighth Hawaii International Conference on System Sciences (HICSS-38). Hawaii: IEEE Press. 
Foot, K. (2001). Cultural-historical activity theory as practice theory: Illuminating the development of a conflict-monitoring network. Communication Theory, 11(1): 56-83.

Foot, K., \& Schneider, S. M. (2006). Web Campaigning. Cambridge, MA: The MIT Press.

Forte, M. (2004). Co-construction and field creation: Web site development as both an instrument and relationship in action research. In E. A. Buchanan (Ed.), Readings in virtual research ethics: Issues and controversies, pp. 222-248. Hershey, PA: Idea Group.

Gonsalves, A. (2007). Microsoft's open-source strategy coming into focus. Information Week (July 30).

Herring, S. (2004). Computer-mediated discourse analysis: An approach to researching online behavior. In S. A. Barab, R. Kling, \& J. H. Gray, (Eds.), Designing for virtual communities in the service of learning, pp. 338-376. New York: Cambridge University Press.

Latour, B. (1991). Technology is Society Made Durable. In J. Law (Ed.), A Sociology of Monsters: Essays on power, technology and domination, pp.103-131. London: Routledge.

Latour, B. (2005). Reassembling the social: An introduction to actor-networktheory. New York: Oxford University Press.

Latour, B., \& Woolgar, S. (1979). Laboratory Life: The social construction of scientific facts. Beverly Hills: Sage Publications.

Latour, B., \& Woolgar, S. (1986). Laboratory Life: The construction of scientific facts. Princeton, NJ: Princeton University Press.

Miettinen, R. (1999). The riddle of things: Activity theory and actor network theory as approaches to studying innovations. Mind, Culture, and Activity, 6, 170-195.

Nentwich, M. (2003). Cyberscience: Research in the Age of the Internet. Vienna: Austrian Academy of Sciences Press.

Raymond, E. S. (2001). The cathedral \& the bazaar: Musings on Linux and open source by an accidental revolutionary (Revised \& Expanded ed.). Sebastopol, CA: O'Reilly Media.

Rogers, R. (2004). Information politics on the Web. Cambridge, MA: MIT Press.

Sismondo, S. (2004). An Introduction to science and technology studies. Oxford: Blackwell Publishing.

Wouters, Vann, K., Scharnhorst, A., Ratto, M., Hellsten, I., Fry, J., et al. (2007). Messy shapes of knowledge-STS explores informatization, new media, and academic work. In E. J. Hackett, O. Amsterdamska, M. Lynch, \& J. Wajcman (Eds.), The handbook of science and technology studies, Third Edition, pp. 319-362. Cambridge, MA: MIT Press.

Wouters, P., \& Beaulieu, A. (2007). Critical accountability: Dilemmas for interventionist studies of e-science. Journal of Computer Mediated Communication, 12(2). http://jcmc.indiana.edu/vol12/issue2/wouters.html 